\title{
USULAN PERBAIKAN KUALITAS PRODUK PLASTIK DENGAN METODE QUALITY FUNCTION DEPLOYMENT DI PT. X
}

\author{
I Wayan Sukania, Lithrone Laricha Salomon dan Oki Dharmawan \\ Program Studi Teknik Industri Universitas Tarumanagara \\ Jl. Let. Jend S. Parman No.1, Jakarta 11440 \\ e-mail: wayans@ft.untar.ac.id
}

\begin{abstract}
ABSTRAK
PT. X merupakan perusahaan yang bergerak dalam bidang produksi produk yang terbuat dari bijih plastik dengan menggunakan mesin injection dan injection blowing molding. Dalam proses produksinya sering ditemukan berbagai jenis defect. Berdasarkan hasil pengolahan data, jenis defect yang mendapatkan prioritas perbaikan adalah flashes dan short shot dengan persentasenya masing-masing sebesar 12,55\% dan 2,19\%. Tingkat Sigma yang didapatkan untuk seluruh produk sebesar 3,12 Sigma. Hasil penelitian sementara dari metode Failure Mode and Effect Analysis menunjukkan penyebabpenyebab utama dari flashes adalah mold yang sudah melebihi life-time, ejector pin yang sudah aus dan konstruksi mold yang tidak sesuai dengan aliran material dengan nilai RPN berurutan sebesar 95,04; 95,04; 88,16. Kemudian, dari analisis menggunakan Quality Function Deployment didapatkan technical responses yang harus diprioritaskan untuk mengurangi defect adalah penggunaan material baja yang diharden, desain mold dibuat dengan baik terutama pada bagian stripper, guide pin dan slider, pemeriksaan ukuran yang teliti terhadap mold, dan pertemuan antara cavity, stripper dan core plate harus bersentuhan pada seluruh bagian dengan nilai prioritas masing-masing sebesar 15,04\%, 11,66\%, $10,35 \%$ dan $10,35 \%$.
\end{abstract}

Kata Kunci: Defect, Six Sigma, FMEA, QFD

\begin{abstract}
PT. $X$ is a company that engaged in production of products that made of plastic materials using injection molding machines. In the production process, various types of defects are often found. According to the results of data processing, types of defects that have to be prioritized are flashes and short shot with respective percentages are $12.55 \%$ and $2.19 \%$. The level of Sigma obtained by all products is 3.12 sigma. The temporary result using Failure Mode and Effect Analysis method shows that the main causes of flashes and short shot are mold that have excess life-time, the worn-out ejector pin and the construction of mold is not compatible with the flow of material with respective RPN are 95.04; 95.04; 88.16. Then, from the Quality Function Deployment approach shows technical responses that have to be prioritized to decrease the defects are using the steel material that have been harden, a good mold design especially on stripper, guide pin and slider parts, the inspection of the dimention of molds and the parting line of cavity, stripper and core plate, and with respective priority score are $15.04 \%, 11.66 \%, 10.35 \%$ dan $10.35 \%$
\end{abstract}

Keywords: Defect, Six Sigma, FMEA, QFD

\section{PENDAHULUAN}

PT. X merupakan perusahaan yang bergerak dalam bidang pembuatan produk houseware yang terbuat dari plastik. Dalam menghasilkan produk-produk plastiknya, PT. X sering menemukan berbagai jenis defect yang menyebabkan adanya pekerjaan tambahan yaitu finishing dan rework. Jenis-jenis defect yang terjadi adalah defect flashes, defect short shot dan defect uneven color. Jadi, pengendalian kualitas baru dilakukan setelah ditemukannya kecacatan produk dalam proses produksi yang berjalan. Saat ini juga belum banyak alternatif yang dilakukan untuk melakukan tindakan pencegahan terhadap faktor-faktor yang berpengaruh terhadap kualitas produk pada saat produksi sehingga penurunan kualitas sampai dengan terjadinya kecacatan produk masih banyak ditemukan.

Sehingga tujuan dari dilakukannya penelitian ini adalah untuk mengetahui jenis defect produk yang harus mendapatkan perbaikan, mengetahui faktor-faktor yang mempengaruhi terjadinya defect produk plastik, mendapatkan usulan yang tepat untuk menangani cacat yang terjadi pada produk 
plastik dan untuk mendapatkan pengembangan faktor-faktor produksi yang tepat sehingga dapat mengurangi penurunan kualitas produk botol plastik.

\section{Kualitas}

Garvin (1984), membagi pengertian dari kualitas menjadi lima kategori yaitu: transcendent, product-based, user-based, manufacturing based, dan value based. Kualitas juga dapat diartikan seperti berikut: Kualitas dari sebuah produk atau jasa adalah kesesuaian dari produk atau jasa tersebut untuk memenuhi atau melebihi fungsinya yang dibutuhkan oleh pelanggan [1]. Kualitas sangat erat hubungannya dengan Six Sigma.

\section{Six Sigma}

Six Sigma bertujuan untuk mereduksi variasi, pengendalian proses dan peningkatan terus menerus. Six Sigma adalah tingkat performansi proses dimana nilai rata-rata nya berada di antara batas atas dan bawah dari pelanggan serta memiliki variasi yang sangat kecil, yaitu 12 kali standar deviasi berada di antara batas atas dan bawah pelanggan [2].

\section{Diagram Pareto}

Diagram pareto adalah sebuah diagram batang yang dipadukan dengan diagram garis untuk merepresentasikan suatu parameter yang diukur (bisa berupa frekuensi kejadian atau nilai tertentu) sehingga dapat diketahui parameter yang dominan [1].

\section{Diagram Fishbone}

Diagram fishbone adalah suatu diagram yang menunjukkan hubungan antara sebab dan akibat. Berkaitan dengan pengendalian proses stastistikal, diagram fishbone digunakan untuk menunjukkan faktor-faktor penyebab (sebab) dan karakteristik kualitas (akibat) yang disebabkan oleh faktor-faktor penyebab itu [1].

\section{Failure Mode and Effect Analysis (FMEA)}

FMEA adalah salah satu metodologi untuk menganalisis resiko yang direkomendasi oleh standar internasional. Metode FMEA adalah proses sistematik untuk mengidentifikasi kegagalan yang mungkin terjadi dalam mencapai tujuan yang telah ditentukan, mengidentifikasi penyebab terjadi kegagalan untuk menghilangkan penyebabnya dan mengidentifikasi dampak dari kegagalan sehingga dapat mengurangi dampak dari kegagalan tersebut [3].

\section{Quality Function Deployment (QFD)}

QFD merupakan suatu alat yang banyak digunakan dalam dunia industri untuk meningkatkan perencanaan produk serta pengembangan proses dan produk itu sendiri. Alat perencanaan utama yang digunakan dalam QFD adalah penggunaan House of Quality (HOQ). HOQ dapat menerjemahkan "voice of customer" ke dalam keperluan perancangan yang dapat memenuhi target yang spesifik dan sesuai dengan bagaimana sebuah organisasi akan memenuhi keperluan tersebut [4].

\section{METODE PENELITIAN}

Tempat penelitian yang dipilih adalah PT. X. Jenis data yang digunakan adalah data primer dan data sekunder. Sumber data primer berasal dari hasil wawancara langsung dengan perwakilan dari departemen-departemen yang berhubungan langsung dengan kualitas produk dan pembuatan mold. Sedangkan sumber data sekunder berasal dari data historis dari perusahaan berupa data jumlah dan jenis-jenis defect selama bulan Maret hingga Agustus 2016. Sumber data sekunder yang lainnya juga berasal dari studi pustaka dari referensi yang didapatkan dari buku dan jurnal dari internet. Adapun tahapan penelitian berturut-turut yaitu mendata jumlah dan jenis cacat bulan MaretAgustus 2016, wawancara dan pengisian kuesioner FMEA, pengolahan data dan usulan perbaikan.

\section{HASIL DAN PEMBAHASAN Defect Flashes}

Flashes adalah jenis defect dimana adanya kelebihan bahan yang terbentuk pada produk yang tidak sesuai dengan desain produk awal. Flashes dapat terjadi karena kebocoran pada mold sehingga material plastik keluar pada pertemuan cetakan atau lubang pin ejector. 


\section{Defect Short Shot}

Short shot adalah jenis defect dimana produk tidak terbentuk atau mengalami proses secara sempurna sehingga produk tidak terbentuk secara utuh.

\section{Defect Uneven Color}

Uneven color adalah jenis defect dimana warna produk yang telah diproduksi tidak sesuai dengan desain awal. Warna produk bisa lebih muda atau lebih tua dari warna yang ditentukan.

\section{Analisis dengan Diagram Pareto}

Dari diagram pareto yang dapat dilihat pada Gambar 2, dapat diketahui defect yang paling banyak terjadi yaitu defect flashes. Defect terbesar kedua adalah defect short shot.

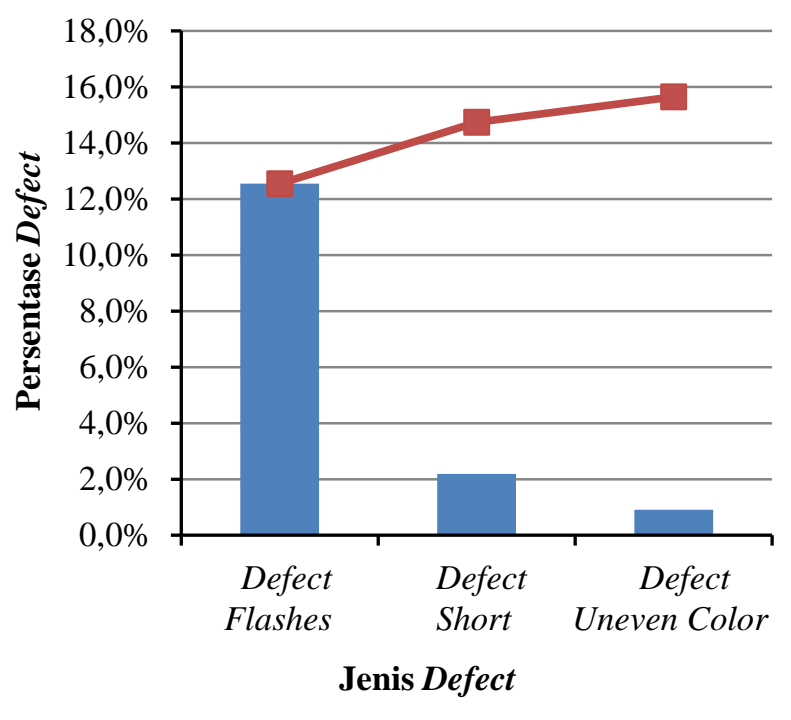

Gambar 1. Diagram Pareto untuk defect

\section{Kapabilitas Proses}

Kapabilitas proses dilakukan dengan menghitung Cp dan Cpk. Perhitungan peta kendali $\mathrm{P}$ sebelumnya didapatkan nilai $\mathrm{p}$ sebesar 0,1565. Jadi, persentase proporsi cacatnya adalah 15,65.

$a=1-\frac{\text { persentase proporsi cacat }}{100 \times \text { opportunities cacat }}$

$a=1-\frac{15,65}{100 \times 3}=0,947833$
Nilai a adalah 0,947833, kemudian dicari pada table distribusi normal dan diperoleh nilai $\mathrm{Z}=1,62$. Selanjutnya adalah menghitung nilai Cp:

$C p=\frac{\text { Titik } Z}{3}$

$C p=\frac{1,62}{3}=0,54$

Setelah dilakukan perhitungan, nilai Cp yang didapatkan adalah 0,54. Selanjutnya adalah menghitung nilai Cpk:

$a=1-\frac{\text { persentase proporsi cacat }}{100}$

$a=1-\frac{15,65}{100}=0,8435$

Nilai a adalah 0,8435, kemudian dicari pada table distribusi normal dan diperoleh nilai $\mathrm{Z}=1,01$

$C p_{k}=\frac{\text { Titik } Z}{3}$

$C p_{k}=\frac{1,01}{3}=0,3367$

Nilai Cp yang didapatkan sebesar 0,54 dan untuk nilai Cpk yang didapatkan sebesar 0,3367. Nilai ini menunjukkan bahwa produk yang dihasilkan masih kurang baik sehingga memerlukan perbaikan kualitas pada proses produksi agar produk yang dihasilkan dapat bertambah baik kualitasnya.

\section{Perhitungan DPMO}

Perhitungan DPMO dilakukan untuk menentukan tingkat Sigma pada PT. X. Berikut ini merupakan perhitungan DPMO yang dapat dilihat pada Tabel 1.

\section{Analisis dengan Cause Failure Mode and Effect Diagram}

Dari Gambar 2 dapat dijelaskan bahwa terdapat beberapa sebab dan akibat yang akhirnya memungkinkan terjadinya flashes. 
Penyebab yang pertama adalah adanya kebocoran pada mold. Kebocoran pada mold dapat terjadi karena dua penyebab yaitu ejector pin yang sudah aus dan parting line pada mold yang sudah tidak tertutup dengan rapat. Parting line yang tidak tertutup dengan rapat disebabkan oleh core dan cavity plate yang sudah aus. Bagian yang telah aus pada mold dapat menyebabkan kebocoran karena terdapat rongga yang terbentuk akibat tekanan yang terus menerus dalam proses produksi. Core dan cavity plate yang aus disebabkan karena mold yang digunakan telah melebihi life-time-nya.

Tabel 1. Perhitungan DPMO Produk Plastik Bulan Maret-Agustus 2016

\begin{tabular}{lc}
\hline \multicolumn{1}{c}{ Keterangan } & Produk Plastik \\
\hline Unit & 1.067 .525 pcs \\
\hline Opportunities & 3 \\
\hline Defect & 167.075 \\
\hline Defect Per Unit & 0,15650 \\
\hline Total Opportunities & 3202575 \\
\hline Defect Per Opportunities & 0,05216 \\
\hline DPMO & 52168,95779 \\
\hline Tingkat Sigma & 3,12 Sigma \\
\hline
\end{tabular}

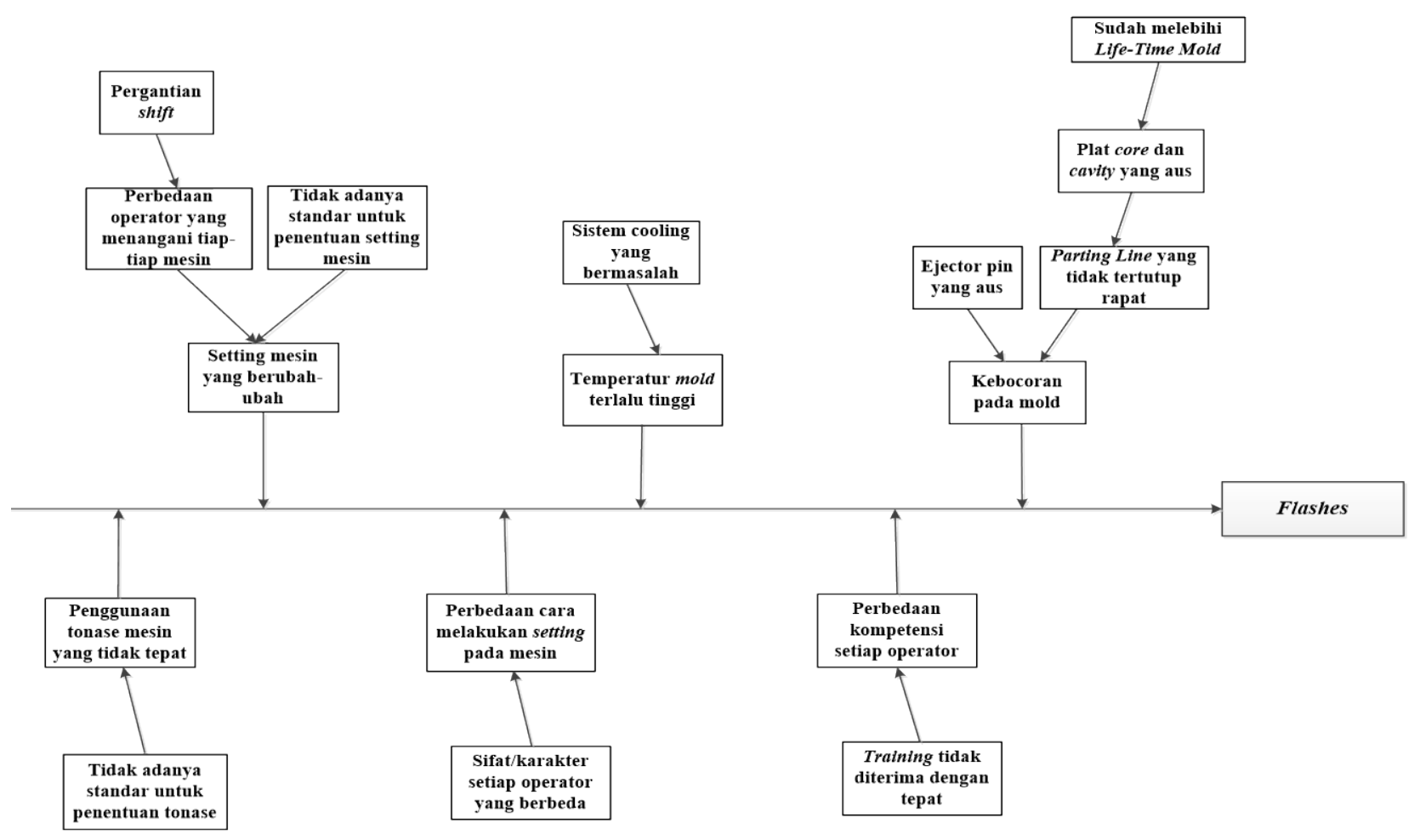

Gambar 2. Cause Failure Mode and Effect Diagram Defect Flashes
Penyebab kedua adalah temperatur mold yang terlalu tinggi. Temperatur mold yang terlalu tinggi dapat disebabkan oleh sistem cooling pada mold yang bermasalah. Temperatur mold yang terlalu tinggi menyebabkan material sulit untuk membeku sehingga material akan mengalir keluar karena sudah memenuhi seluruh rongga pada mold. Penyebab ketiga adalah setting parameter mesin yang berubah-ubah yang dapat terjadi karena perbedaan operator yang menangani tiap-tiap mesin dan tidak adanya standar penentuan setting mesin yang berlaku. Perbedaan operator yang menangani mesin disebabkan oleh adanya pergantian shift kerja.

Penyebab keempat adalah penggunaan tonase mesin yang tidak sesuai yang terjadi karena tidak adanya standar dalam penentuan tonase mesin. Penyebab kelima adalah perbedaan cara melakukan setting mesin oleh para operator karena pada dasarnya setiap operator memiliki sifat/karakter yang berbedabeda. Penyebab keenam adalah perbedaan kompetensi setiap operator yang dimiliki oleh perusahaan. Perbedaan kompetensi disebabkan oleh adanya kemungkinan para operator tidak menerima training dengan baik dan tepat. 


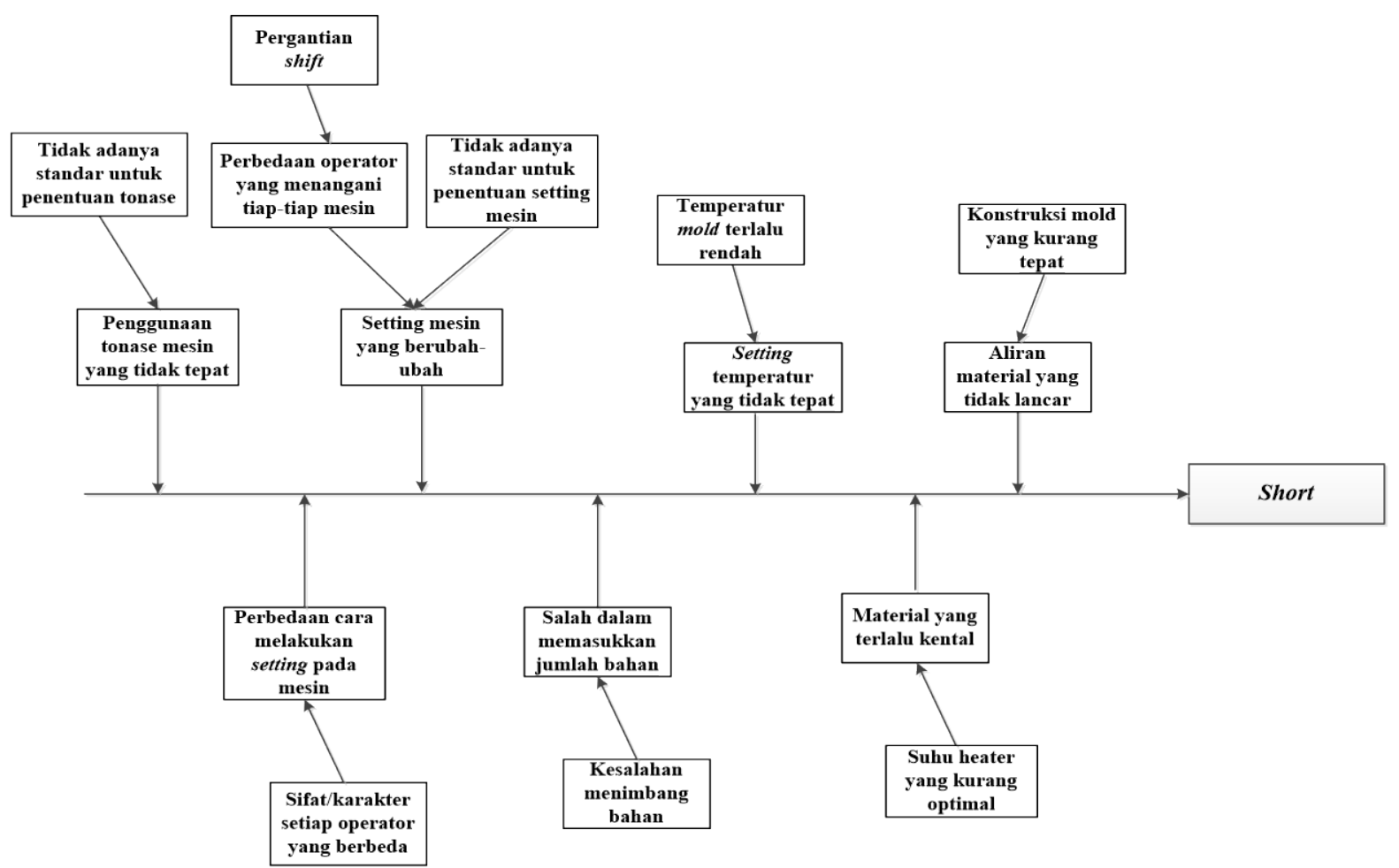

Gambar 3. Cause Failure Mode and Effect Diagram Defect Short Shot

Kemudian dari Gambar 3, dapat dijelaskan juga terdapat beberapa sebab dan akibat yang memungkinkan terjadinya short shot pada produk. Penyebab pertama adalah aliran material yang tidak lancar yang disebabkan oleh konstruksi mold yang tidak sesuai dengan aliran material sehingga material tidak dapat memenuhi mold untuk membentuk produk. Penyebab kedua adalah setting temperatur pada mold yang terlalu rendah yang mengakibatkan material membeku sebelum memenuhi rongga pada mold. Penyebab ketiga adalah setting parameter mesin yang berubahubah yang dapat terjadi karena perbedaan operator yang menangani tiap-tiap mesin dan tidak adanya standar penentuan setting mesin yang berlaku. Perbedaan operator yang menangani mesin disebabkan oleh adanya pergantian shift kerja.

Penyebab keempat adalah penggunaan tonase mesin yang tidak sesuai yang terjadi karena tidak adanya standar dalam penentuan tonase mesin. Penyebab kelima adalah perbedaan cara melakukan setting mesin oleh para operator karena pada dasarnya setiap operator memiliki sifat/karakter yang berbedabeda. Penyebab keenam adalah kesalahan dalam memasukkan jumlah bahan ke dalam mold dalam setiap shot. Kesalahan ini disebabkan oleh kesalahan dalam penentuan angka shot size pada setting mesin. Jumlah material yang tidak mencukupi untuk membentuk satu produk pasti akan menyebabkan short shot. Penyebab keenam adalah kekentalan material yang terlalu tinggi yang disebabkan oleh suhu heater pada nozzle yang masih terlalu rendah.

Setelah mengidentifikasi penyebabpenyebab dari flashes dan short shot, dilanjutkan dengan wawancara menggunakan kuesioner FMEA untuk mengetahui tingkat keparahan (severity), frekuensi kejadian (occurrence) dan detection untuk mendapatkan penyebab-penyebab utama yang lebih diprioritaskan melalui penentuan nilai RPN.

\section{Failure Mode and Effect Analysis untuk Proses Injection}

FMEA digunakan untuk menganalisis dan memberi nilai RPN bagi kegagalan yang sering terjadi sehingga didapatkan ranking untuk penyebab-penyebab terjadinya kegagalan yang akan dipilih untuk ditangani lebih lanjut guna mengurangi kemungkinan terjadinya kegagalan. Tabel FMEA dapat dilihat pada Tabel 2. 
Penyebab terjadinya kegagalan proses yang memiliki nilai RPN tertinggi adalah mold yang sudah melebihi life-time, ejector pin yang sudah aus dan konstruksi mold yang tidak sesuai dengan aliran material dengan nilai RPN berturut-turut adalah 95,04; 95,04; 88,16. Penyebab terjadinya kegagalan proses yang memiliki RPN tertinggi berhubungan langsung dengan mold sehingga proses perbaikan akan dilakukan terhadap injection molding pada tahap selanjutya dengan metode Quality Function Deployment.

\section{Quality Function Deployment}

Hasil penelitian sementara dengan metode Quality Function Deployment dapat dilihat pada House of Quality (HOQ). HOQ merupakan gabungan dari beberapa matriks yang saling berhubungan antara satu dengan yang lainnya. Perancangan HOQ digunakan untuk mendapatkan usulan yang harus diprioritaskan untuk memperbaiki dan mengembangkan kualitas dari injection molding yang belum tercapai sebelumnya. HOQ pada penelitian ini dapat dilihat pada Gambar 4.

\begin{tabular}{|c|c|c|}
\hline \multicolumn{3}{|c|}{ Hubungan antar Technical Responses } \\
\hline$\oplus$ & Strong Positive & +9 \\
\hline+ & Positive & +3 \\
\hline- & Negative & -3 \\
\hline$\ominus$ & Strong Negative & -9 \\
\hline
\end{tabular}
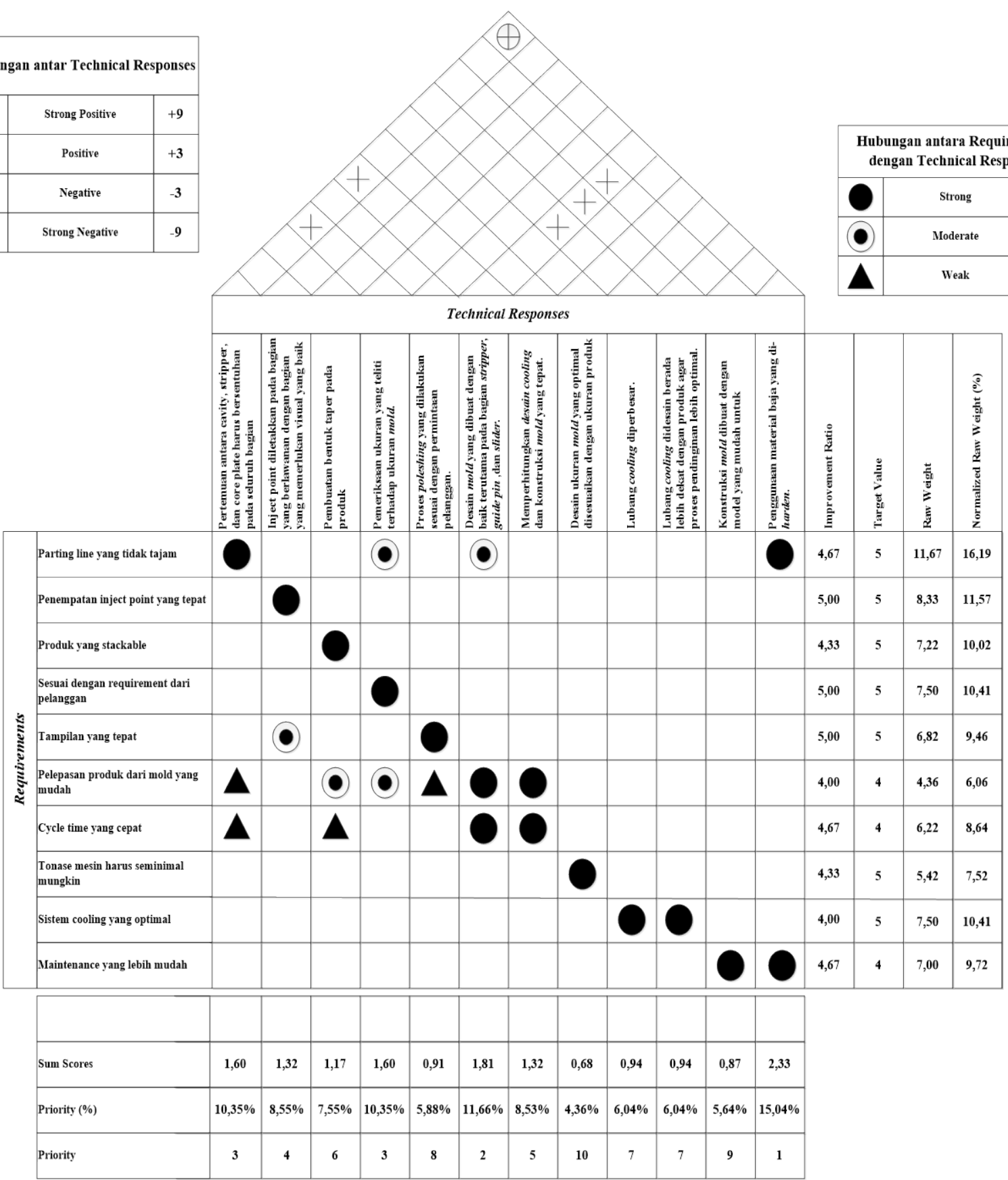

Gambar 4. HOQ Usulan 
Tabel 2. Tabel FMEA

\begin{tabular}{|c|c|c|c|c|c|c|c|}
\hline $\begin{array}{l}\text { Fungsi } \\
\text { Proses }\end{array}$ & $\begin{array}{c}\text { Jenis } \\
\text { Kegagalan } \\
\text { Pada Proses } \\
\end{array}$ & $\begin{array}{c}\text { Efek dari } \\
\text { Kegagalan yang } \\
\text { Terjadi } \\
\end{array}$ & $\mathbf{S}$ & Penyebab Kegagalan Proses & $\mathbf{O}$ & $\mathbf{D}$ & RPN \\
\hline \multirow{12}{*}{ Injection } & \multirow{8}{*}{ Flashes } & \multirow{8}{*}{$\begin{array}{l}\text { Memerlukan } \\
\text { pekerjaan } \\
\text { finishing }\end{array}$} & \multirow{8}{*}{4} & Mold yang sudah melebihi life-time & 7 & 4 & 112 \\
\hline & & & & Ejector pin yang aus & 7 & 4 & 112 \\
\hline & & & & Sistem cooling yang bermasalah & 3 & 3 & 36 \\
\hline & & & & $\begin{array}{l}\text { Tidak adanya standar untuk penentuan setting } \\
\text { mesin }\end{array}$ & 6 & 1 & 24 \\
\hline & & & & $\begin{array}{l}\text { Tidak adanya standar untuk penentuan tonase } \\
\text { mesin }\end{array}$ & 6 & 1 & 24 \\
\hline & & & & Training yang tidak diterima dengan tepat & 2 & 9 & 72 \\
\hline & & & & $\begin{array}{l}\text { Konstruksi mold yang tidak sesuai dengan } \\
\text { aliran material }\end{array}$ & 6 & 4 & 96 \\
\hline & & & & Setting temperatur mold yang tidak tepat & 6 & 1 & 24 \\
\hline & \multirow{4}{*}{ Short Shot } & \multirow{4}{*}{ Rework } & \multirow{4}{*}{7} & $\begin{array}{c}\text { Tidak adanya standar untuk penentuan setting } \\
\text { mesin }\end{array}$ & 6 & 2 & 84 \\
\hline & & & & $\begin{array}{l}\text { Tidak adanya standar untuk penentuan tonase } \\
\text { mesin }\end{array}$ & 6 & 1 & 42 \\
\hline & & & & Kesalahan dalam menimbang bahan & 6 & 1 & 42 \\
\hline & & & & Kesalahan dalam menentukan suhu heater & 6 & 1 & 42 \\
\hline Finishing & $\begin{array}{c}\text { Produk yang } \\
\text { tidak sesuai } \\
\text { ukuran } \\
\end{array}$ & Rework & 7 & Finishing dengan menggunakan cutter & 10 & 5 & 350 \\
\hline
\end{tabular}

\section{KESIMPULAN}

Kesimpulan dari penelitian pada PT. X yaitu berdasarkan diagram pareto, jenis defect yang harus mendapatkan prioritas perbaikan adalah flashes dan short shot dengan persentase terjadinya masing-masing sebesar 12,55\% dan 2,19\%. Kemudian berdasarkan Tabel FMEA, penyebab terjadinya kegagalan proses yang memiliki nilai RPN tertinggi adalah mold yang sudah melebihi life-time, ejector pin yang sudah aus dan konstruksi mold yang tidak sesuai dengan aliran material dengan nilai RPN berturut-turut adalah 95,04; 95,04; 88,16. Penyebab terjadinya kegagalan proses di atas berhubungan langsung dengan injection molding.

Berdasarkan House of Quality, didapatkan usulan untuk perbaikan dan pengembangan injection molding dengan meningkatkan technical responses yang menjadi prioritas tertinggi yaitu penggunaan material baja yang di-harden, desain mold dibuat dengan baik terutama pada bagian stripper, guide pin dan slider, pemeriksaan ukuran yang teliti terhadap mold, dan pertemuan antara cavity, stripper dan core plate harus bersentuhan pada seluruh bagian dengan nilai prioritas masing-masing sebesar 15,04\%, 11,66\%, 10,35\% dan 10,35\%.

\section{DAFTAR PUSTAKA}

[1] Mitra, Amitava. 2008. Fundamentals of Quality Control and Improvement. Third Edition. John Wiley \& Sons, Inc: New Jersey.

[2] Gupta, Praveen. 2005. The Six Sigma Performance Handbook. McGraw-Hill Companies, Inc: USA.

[3] Library of Congress. 2013 Guidelines for Failure Mode and Effects Analysis for Automotive, Aerospace and General Manufacturing Industries. CRC Press: Florida.

[4] Besterfield, Dale H., Carol BesterfieldMichna, Glen H. Besterfield, Mary Besterfield-Sacre. 2003. Total Quality Management. Third Edition. Pearson Education, Inc: New Jersey. 